Claremont Colleges

Scholarship@ Claremont

All HMC Faculty Publications and Research

HMC Faculty Scholarship

$1-1-2001$

\title{
Proof Without Words: The Pigeonhole Principle
}

Ran Libeskind-Hadas

Harvey Mudd College

\section{Recommended Citation}

R. Libeskind-Hadas, "Proof Without Words: The Pigeonhole Principle," Mathematics Magazine, Vol. 75, No. 1, November 2001, page 32.

This Article is brought to you for free and open access by the HMC Faculty Scholarship at Scholarship @ Claremont. It has been accepted for inclusion in All HMC Faculty Publications and Research by an authorized administrator of Scholarship @ Claremont. For more information, please contact scholarship@cuc.claremont.edu. 


\section{Proof Without Words: The Pigeonhole Principle}

RAN LIBESKIND-HADAS

Harvey Mudd College Claremont, CA 91711

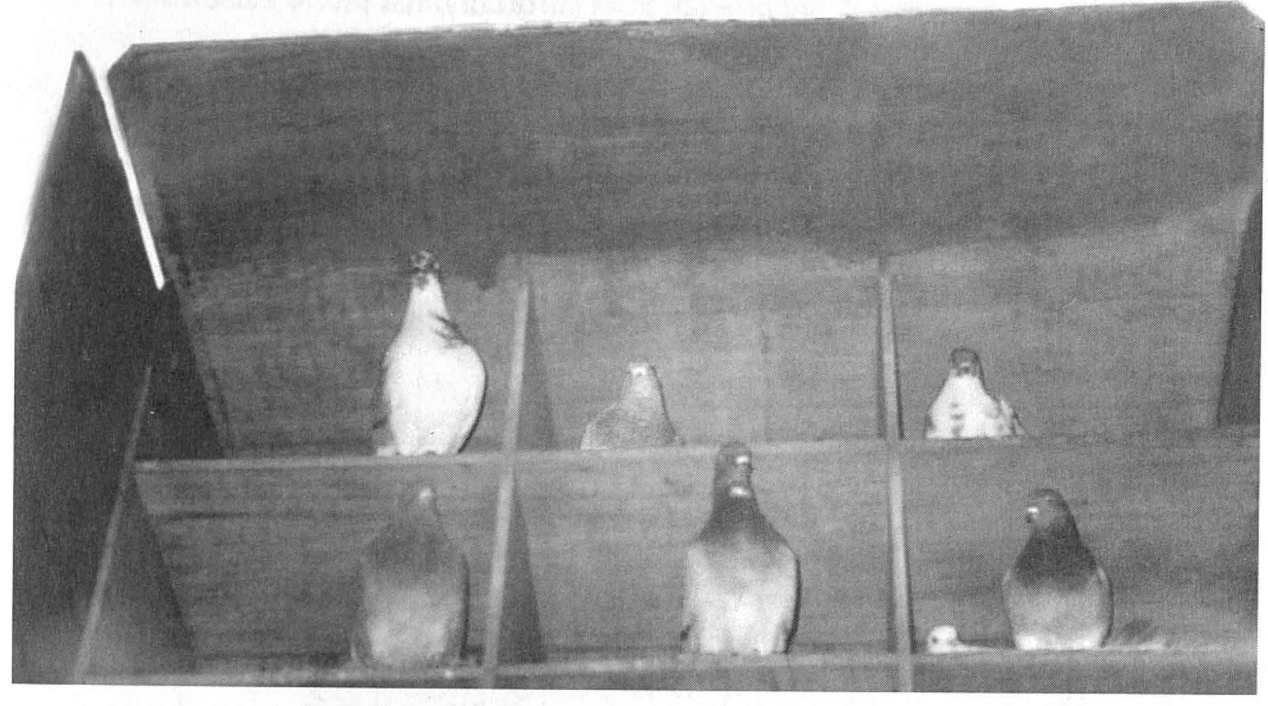

Seven pigeons in six boxes

Letter to the Editor

Dear Editor:

The article by Dresden in the October 2001 issue presents a solution to the problem of the periodicity of the sequence of rightmost nonzero digits of $n$ !. This problem has appeared in several places. I first learned about it from Crux Mathematicorum 19 (1993), 260-261 and 20 (1994) 45, where is was presented as an unused Olympiad problem. A discussion of the problem that focuses on the issue of a fast algorithm to get, say, the rightmost nonzero digit of the factorial of a googol appears as Problem 90 in my book Which Way Did the Bicycle Go? (with D. Velleman and J. Konhauser, MAA, 1996). And in Exercise 4.40 of Concrete Mathematics by Graham, Knuth, and Patashnik (Addison-Wesley, 1989) one finds a formula (see also Problem 90.2 of my book) for this digit in base $p$, when $p$ is prime.

Stan Wagon

Macalester College

St. Paul, MN 55105

wagon@macalester.edu 